\title{
Measuring the accuracy of the Retail Sales Index
}

Joseph Winton and Jeff Ralph

Office for National Statistics

\section{Summary}

A measure of the accuracy of the Retail Sales Index (RSI) has been produced by estimating the standard errors of index movements. This article reports on the calculation of standard errors for one-month and 12-month movements in the RSI. It provides an overview of standard errors and their meaning in the context of the RSI.

\section{Introduction}

The Retail Sales Index (RSI) is a monthly index published by the Office for National Statistics (ONS) measuring the value and volume of retail sales in Great Britain. A method for estimating the standard errors of movement for indices over any fixed period has been developed by ONS and applied to a number of ONS indices over the last few years, including the Index of Production (see Wood et al 2006) and the Producer Price Index (see Morris and Green 2007). The method has now also been adapted for the RSI. An indicative standard error for the whole retail sector for 2009 is estimated as 0.4 per cent for one-month movement and 0.7 per cent for $12-$ month movement.

\section{What is the RSI?}

The RSI is derived from a monthly survey of 5,000 businesses in Great Britain. The sample represents the whole retail sector and includes all large retailers ${ }^{1}$ and a representative sample of smaller businesses. Collectively all of these businesses cover about 95 per cent of the retail sector in terms of turnover. The main monthly output measures include movement in the value and volume of retail sales for the most recent month compared to the previous month and compared to the same month a year earlier.

The value, or current price, indices record the change since the base period in the value of sales before any adjustment for the effect of price change is taken into account. The volume, or constant price, indices are constructed by removing the effect of price change through the use of deflators taken from the Consumer Price Index. 


\section{Structure of the RSI}

The RSI only covers sales from businesses registered as retailers according to the Standard Industrial Classification (SIC) - this is a way of categorising economic activity into a common structure. Retailing is defined as the sale of goods to the general public for household consumption and does not cover spending on services. The classification scheme is hierarchical, extending down to a five-digit classification at the lowest level, with the whole retail sector as one of the twodigit classifications. The data for the RSI is mainly collected at four-digit SIC level and then aggregated up to levels that are useful for users.

The SIC changes from time-to-time in order to accommodate the emergence of new industries and new products. The RSI was published according to SIC 2003 before February 2010, when it changed to SIC 2007. The analysis of standard errors in this paper was carried out using data from 2008 and 2009 and was therefore calculated under the SIC 2003 scheme.

Before the change to SIC 2007 in February 2010, the RSI Statistical Bulletin published movements of indices for eight different groupings of retail businesses; standard errors have been calculated for each of these groupings (see Figure 1).

\section{Figure $1 \quad$ RSI publication structure}

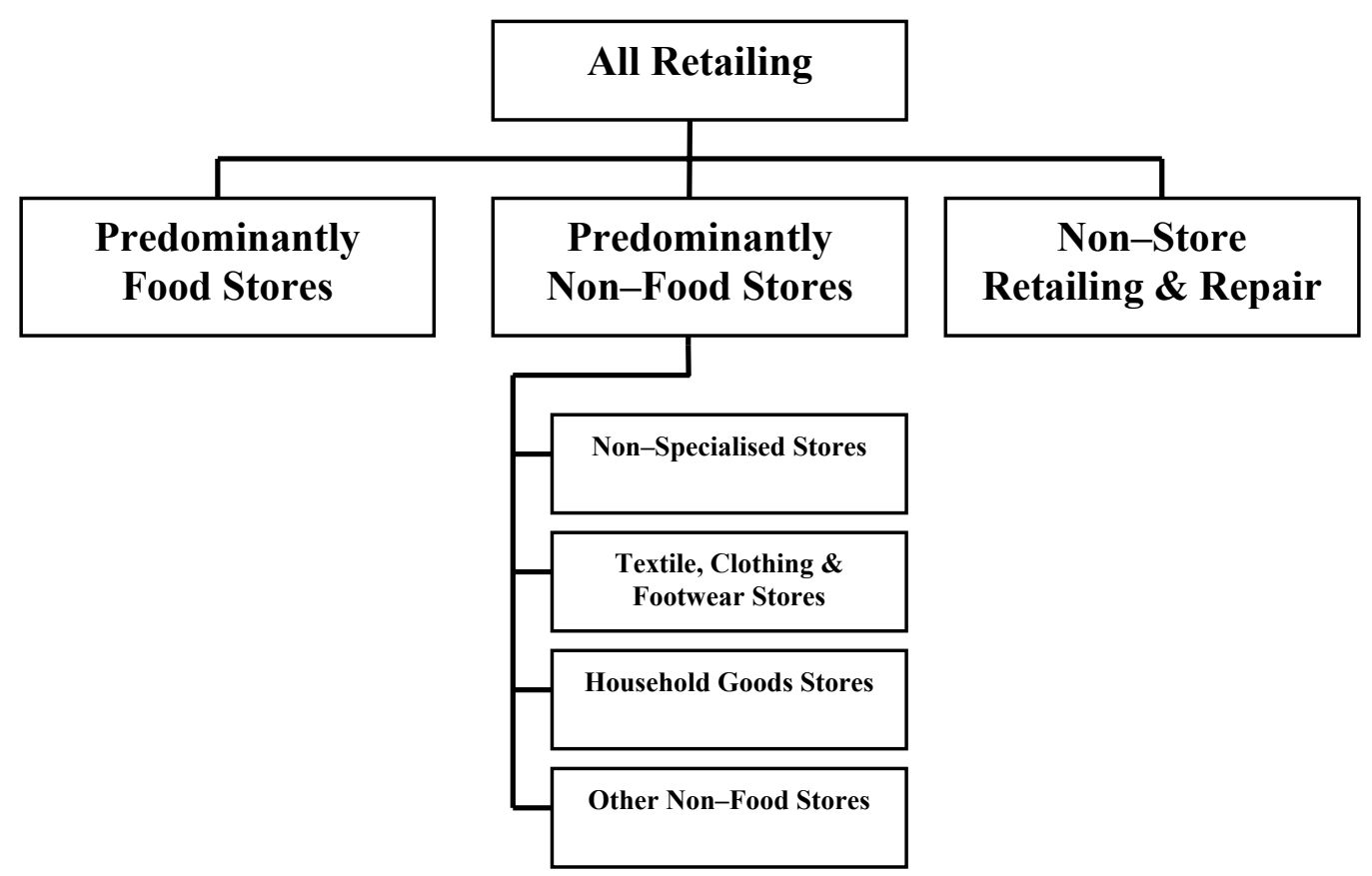




\section{Estimating standard errors of movements in the RSI}

The volume of sales in the RSI is derived by deflating the value of sales ('retail turnover') using the appropriate consumer price indices. When calculating the standard error of movement, the need to incorporate deflation leads to a contribution from consumer price indices as well as a contribution from the retail turnover.

The calculations have been made with non-seasonally adjusted data. The methodology needed to calculate the movement of indices for seasonally adjusted data would be very complex and is beyond the current level of technical development. However, the 12-month movement should not be subject to seasonality, so is unaffected by any complications of seasonal adjustment.

Using 2008 and 2009 retail sales data, the standard errors of the volume of sales for one-month and 12-month movements have been calculated for each month of the year 2009 (see Box 1 for a description of standard error). These standard errors have then been averaged to provide an overall median standard error for one-month movement and 12-month movement. The standard errors do vary from month-to-month; however, there is no discernible pattern to the variation.

The method for estimating the standard error of index movements is based on the application of Taylor linearisation to the formula for the variance of the ratio of indices for two time periods. For more details on the method developed by the ONS, see Bucknall et al 2005 and Wood et al 2006.

\section{Box 1 What is a standard error?}

When calculating the RSI, it would be ideal to collect complete information every month on retail sales for the whole population of retail businesses in Great Britain. The resultant index would be an exact measure of the average growth rate for sales. However, this would be extremely time consuming and expensive and would impose an unacceptable burden on businesses. For this reason, the RSI is based on the value of retail sales from a sample of businesses and is used to provide an estimate of the average growth rate for the population. If a different sample were selected, it would produce a different estimate of the same population growth rate. The difference between an estimate and its true population value is known as the sampling error. The actual sampling error for any estimate is unknown, but from the sample used one can estimate a typical error, known as the standard error.

The standard error of an index movement is a measure of the spread of possible estimates of that movement likely to be obtained when taking a range of different samples of the same size. This provides a means of assessing the accuracy of the estimate: the lower the standard error, the more confident one can be that the estimate of movement is close to the true population value. An approximate 95 per cent confidence interval for the index movement is roughly twice the standard error. 


\section{Analysis and results}

As the standard errors are estimates, they are subject to error; to reduce this error, standard errors have been averaged over the 12-month period ending in 2009.

Table 1 shows the 12-month movement for 'All Retailing' as well as the published sector breakdown in December 2009 together with the corresponding standard errors. The second column shows the median standard errors over all months of 2009. This information is also displayed in Figure 2.

The median standard error for $12-$ month movement of retail sales is 0.7 percentage points. This is heavily influenced by the relatively low standard error of 0.5 percentage points in the 'Predominantly Food Stores' sector which is the dominant sector within 'All Retailing'.

There is a particularly high standard error of movement of 'Non-Store Retailing \& Repair' due to large differences in trading patterns which change monthly in this sector. There is also a high standard error of 3.2 percentage points in the 'Other Stores' sector of 'Predominantly Non-Food Stores'. This is influenced by the large range of different stores included in the sector, which can lead to disparities in volume movements.

\section{Table $1 \quad$ 12-month movements and standard errors}

\begin{tabular}{|c|c|c|}
\hline Sector & $\begin{array}{c}\text { Twelve 12-month movement } \\
\text { December } 2009 \text { (percentage } \\
\text { change) }\end{array}$ & $\begin{array}{l}\text { Standard error of the } 12 \text { - month } \\
\text { movement, } 2009 \text { median } \\
\text { (percentage points) }\end{array}$ \\
\hline All Retailing & 2.1 & 0.7 \\
\hline Predominantly Food Stores & 2.8 & 0.5 \\
\hline Predominantly Non-Food Stores & 0.7 & 1.2 \\
\hline - Non-Specialised Stores & 1.5 & 1.2 \\
\hline - $\quad$ Textile, Clothing and Footwear Stores & 4.7 & 1.0 \\
\hline - $\quad$ Household Goods Stores & 0.4 & 1.8 \\
\hline - $\quad$ Other Stores & -3.0 & 3.2 \\
\hline Non-Store Retailing and Repair & 9.4 & 2.9 \\
\hline
\end{tabular}

Source: Office for National Statistics

Table 2 and Figure 3 display the one-month movement of retail sales for December 2009 (movements are generally biggest from November to December) the published sector breakdown as well as the corresponding standard errors. The median standard error of one-month movement in retail sales is 0.4 percentage points.

The sector breakdown shows a similar breakdown to Table 1, with a relatively low standard error in the 'Predominantly Food Stores' and large standard error in 'Other Stores' and 'Non-Store Retailing \& Repair'. 


\section{Figure 212 month movements, December 2009}

Percentage change with $95 \%$ confidence intervals

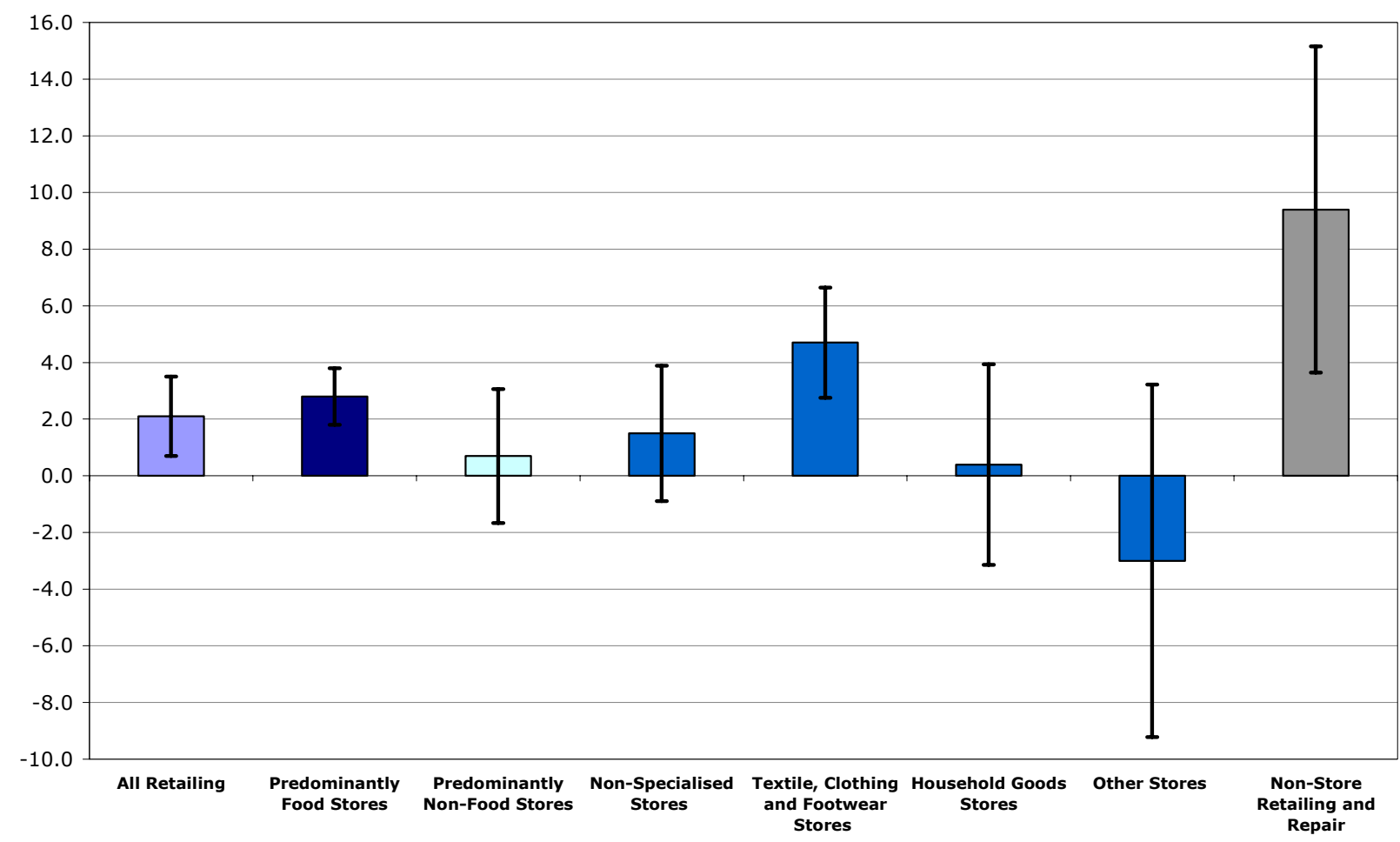

Source: Office for National Statistics

The standard error for the one-month movement for 'All Retailing' is a similar size to the December movement in the index; this indicates that for this period it is difficult to distinguish any real one month movement from random noise. However, the 'All Retailing' 12-month movement (see Table 1 ) is three times the standard error suggesting that there is some distinguishable movement and therefore the annual movement is more clearly identified.

\section{Table 2 One-month movements and standard errors}

\begin{tabular}{|c|c|c|}
\hline Sector & $\begin{array}{c}\text { One-month movement } \\
\text { December } 2009 \text { (percentage } \\
\text { change) }\end{array}$ & $\begin{array}{c}\text { Standard error of the one-month } \\
\text { movement, } 2009 \text { median } \\
\text { (percentage points) }\end{array}$ \\
\hline All Retailing & 0.3 & 0.4 \\
\hline Predominantly Food Stores & 0.3 & 0.2 \\
\hline Predominantly Non-Food Stores & 0.1 & 0.6 \\
\hline - $\quad$ Non-Specialised Stores & -1.0 & 1.0 \\
\hline Textile, Clothing and Footwear Stores & -0.1 & 1.1 \\
\hline - $\quad$ Household Goods Stores & 0.5 & 0.9 \\
\hline - $\quad$ Other Stores & 0.7 & 1.5 \\
\hline Non-Store Retailing and Repair & 2.8 & 3.2 \\
\hline
\end{tabular}

Source: Office for National Statistics 


\section{Figure 3 One-month movements, December 2009}

Percentage change with $95 \%$ confidence intervals

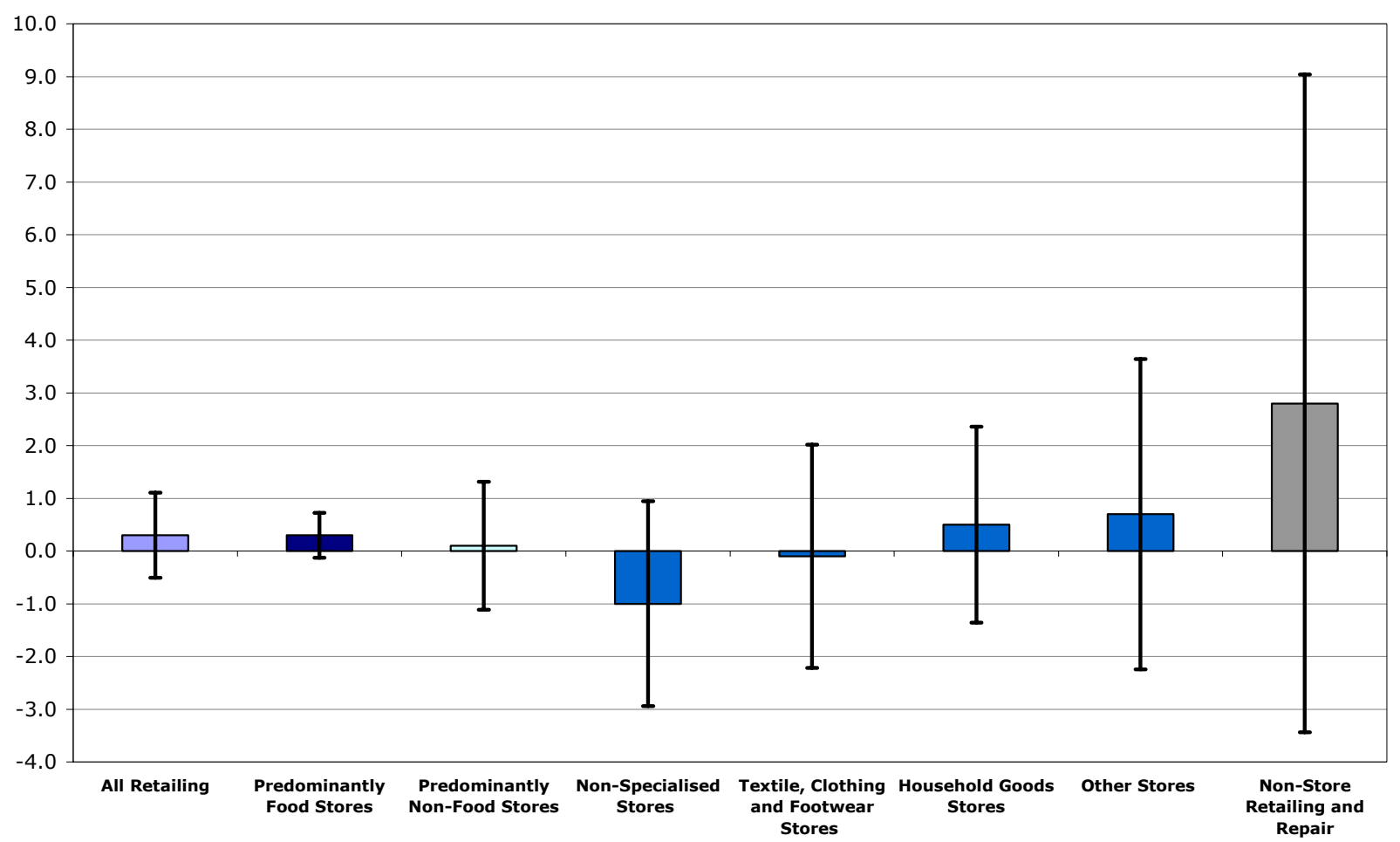

Source: Office for National Statistics

The analysis presented in this paper will be updated to SIC 2007 once sufficient data are available on that basis.

\section{Acknowledgements}

The authors wish to thank Markus Šova, Phil Lewis and Gareth Howell for their significant contributions to this work.

\section{Note}

1. These are retailers with employment exceeding a hundred; also, retailers with smaller employment but turnover exceeding $£ 60$ million. There are 900 large retailers. 


\section{References}

Bucknall R D, Šova M G and Wood J (2005) 'Estimating standard errors of movements in Producer Price Indices', Proceedings of the $10^{\text {th }}$ GSS Methodology Conference, ONS, available at www.statistics.gov.uk/events/gss2005/agenda.asp

Morris J and Green T (2007) 'Measuring the Quality of the Producer Price Index', Economic and Labour Market Review, Vol.1 No. 10, pp 31-35, ONS, available at www.statistics.gov.uk/statbase/product.asp?vlnk $=8127$

Wood J, Šova M G, Parkin N and Bucknall R D (2006) 'Estimation of Standard Errors for the UK Index of Production', Statistical Methodology Bulletin, Issue 59, ONS, available at www.statistics.gov.uk/statbase/Product.asp?vlnk=8127 